\title{
NOTES ON THE THERMAL FACTOR IN THE ECOLOGY OF THE BEET WEBWORM
}

\section{L.G. PUTNAM, 35 Kirk Crescent, Saskatoon, Saskatchewan. S7H 3B1}

Having no internal mechanism for controlling body temperature, insects, with a few exceptions, are subject to whatever the environment offers with respect to heat. The active stages may gain an adavantage in our difficult conditions by exposing themselves to sunlight or extra warm micro-habitats. For example, our pest grasshoppers do best at about $30^{\circ} \mathrm{C}$, and without what they can gain by basking on a warmed-up soil surface in cool sunny weather, they would never make it. Dark colouration may confer an advantage by improving abosorption of direct solar radiation. The Beet Webworm (Loxostege sticticalis L., Lepidoptera:Pyralidae) may be a case in point, since its caterpillars live in the plant canopy, and are not on the soil except when marching. Eggs incubating in the soil, for example those of grasshoppers, and pupae, as in the cocoon of the Beet Webworm, cannot of course adjust; if the soil is shaded by vegetation, progress of development is slowed.

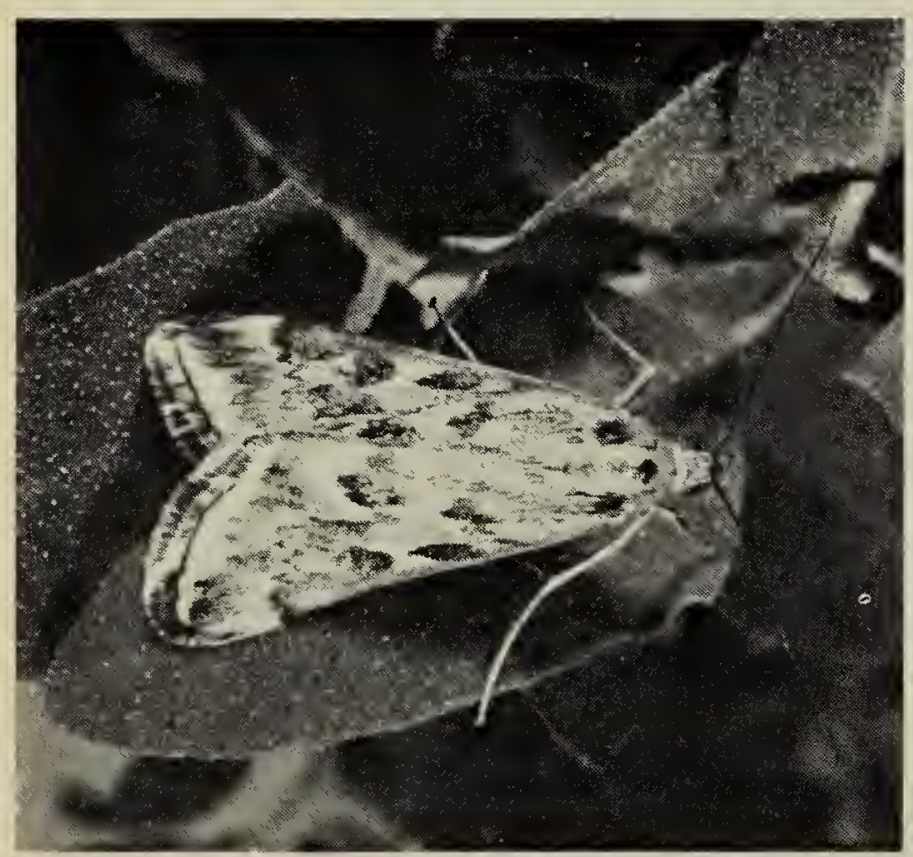

Figure 1. Beet Webworm moth on Lamb's quarters foliage.
Information in the literature on temperature and development in the beet webworm seemed to be fragmentary. The experimental results obtained by the author and presented here are intended to contribute to an understanding of some phenomena related to this species as observed under natural conditions. In another paper, the interaction of temperature and photoperoid in their effects on diapause, the resting stage that the insect may enter, has already been described. ${ }^{1}$ Here, I propose to discuss the effects of temperature on rate of development in Beet Webworm.

To provide data for a time-temperature development curve, rearing from the newlylaid egg through the newly emerged moth was carried out in rearing cabinets at a series of controlled temperatures: 19.5, 20, $20.5,26$, and $30^{\circ} \mathrm{C}$. Times required for development were respectively 58, 52, 42, 29 , and 24 days. These results were of course obtained under photoperiods intended to avert diapause. The three lowest temperatures in the series were closely spaced because it was known that response was sensitive in that range. By extrapolation, it was roughly estimated that the threshold temperature at which development would begin was about $13^{\circ} \mathrm{C}$, but it seems clear that even if development could proceed at that temperature, four or five months would be needed to complete it.

For each whole numbered temperature between 13 and $30^{\circ}$ inclusive, the time required was read off the curve. The percentage of the development accomplished per hour was then calculated. For 13, 14, $\ldots .30^{\circ} \mathrm{C}$ these percentages were $.032, .040$, 
....0.173. These were designated as "hourly developmental increments", and applied later to the results of rearing at fluctuating temperatures.

To investigate fluctuating temperature effects, cultures were reared under two different daily cycling temperature regimes: $9-11$ to $25-26$, and 16 to $29-30^{\circ} \mathrm{C}$. As the programs were designed, no development would be expected for about $9 \mathrm{hr} /$ day under the cooler one. About 74 days were needed to complete development under the cooler program, and 36 under the warmer one. When the calculated hourly increments for each hourly temperature, as recorded on the thermograph, were accumulated, the total accounted for about $95 \%$ of the observed time for the cooler program, and $103 \%$ for the warmer one. Thus the agreement between the expected and observed times was good, although imperfect. Some of the error might have arisen from the crudeness of extrapolation below $19.5^{\circ}$.

In all time-temperature experiments, it was noted that very nearly half the total time in immature stages was spent in the cocoon.

It will be realized that the developmental period as dealt with here does not embrace the entire life cycle, from egg to egg. The pre-oviposition period in the adult moth was not investigated. Under natural conditions, it may be variable.

The results obtained from experiments with cycling temperatures tend to indicate that rate of development is simply the result of accumulated temperature-related developmental increments, with negligible effects attributable to the fact of fluctuation itself.

From the results given here, it would be surprising if the total development of a nondiapausing population in the field could be completed in less than two months. Therefore, a second generation within one season would have to be preceded by an early first on in order to have any success. It is more likely that a second generation either seldom develops or is insignificant in Saskatchewan latitudes.

Light trap captures of beet webworm moths have been recorded for several years and from several points in Saskatchewan. The moth flight usually begins early in June. It may rise to a peak by the middle of the same month, and be followed by another peak a month later; or, the first peak of flight may not occur until mid-July, perhaps followed by another in August. The first or the second peak may be the higher. There is very little evidence of year-to-year regularity in the pattern. The evidence of

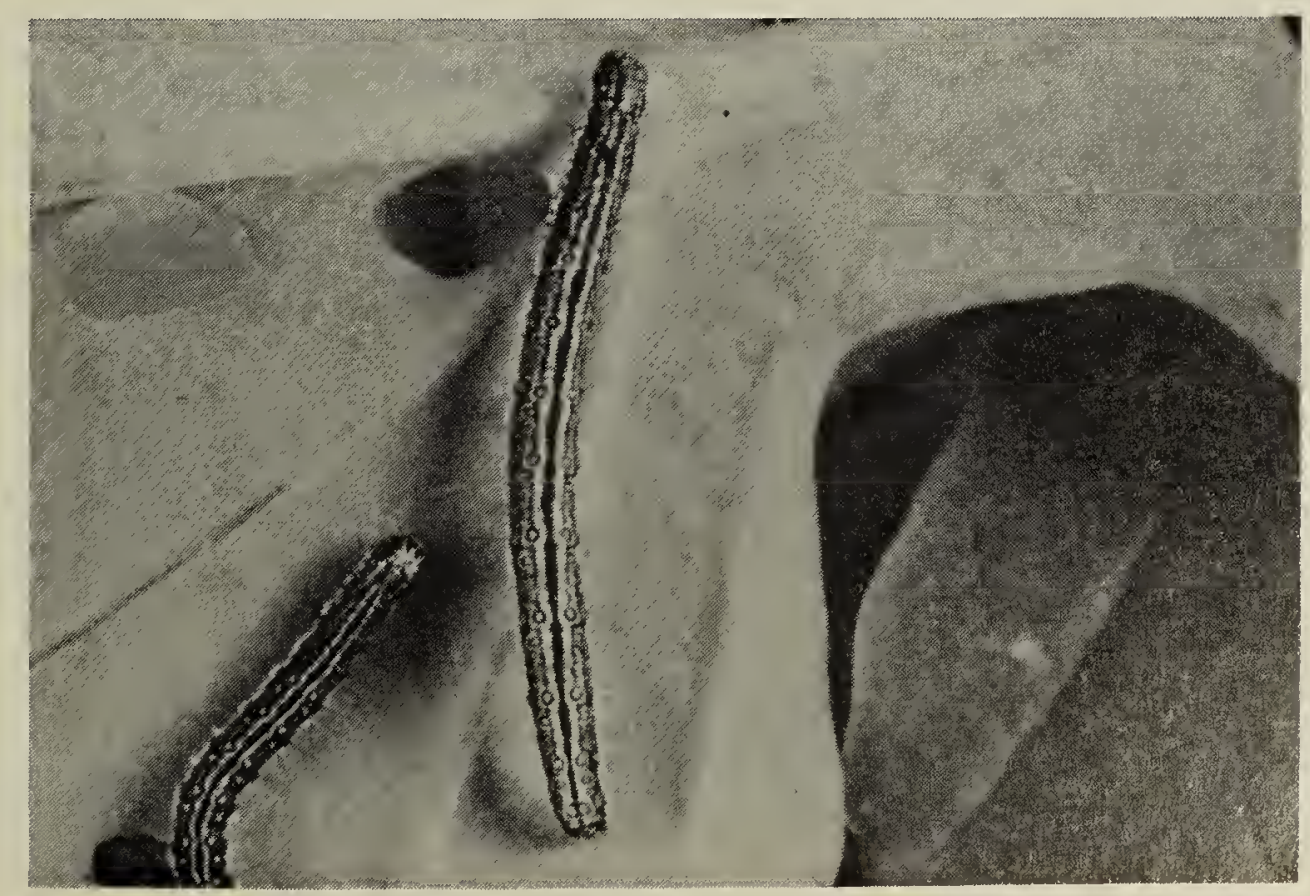

Figure 2. Beet Webworm caterpillars on rapeseed foliage. 
the time required to complete a generation contradicts the temptation to think that the successive peaks represent successive generations. If all the facts of the temperature experience of a population in the cocoons could be known, it might account for a first flight peak in July instead of June, for example, but might not account for two flight peaks separated by a month. Our present knowledge is simply inadequate for an hypothesis concerning this.
The author used equipment and facilities of his former employer the Agriculture Canada Research Station at Saskatoon, in performing the experiments described in this paper. He acknowledges the invaluable assistance of Charles G. Devlin, technician, in their performance.

1 PUTNAM, L.G. 1984. Diapause in the beet webworm. Blue Jay 42(1):22-24.

\title{
CHINESE ELM - A NEW FOOD PLANT FOR THE MOURNING CLOAK BUTTERFLY
}

\author{
WALTER KRIVDA, P.O. Box 864, The Pas, Manitoba. R9A 1 K8
}

Chinese Elm is a rapidly growing foreign tree brought into the Pas area in the past 10 years. It winters well here and seedlings are starting to appear in gardens and along buildings from the adult trees. It has all the appearance of becoming a weed tree and is so treated now by the Saskatchewan Department of Agriculture.

It was something of a surprise this past August to find several dozen almost fully grown larvae of the Mourning Cloak Butterfly on a Chinese Elm hedge on 3rd Street in town. With the able assistance of my sixyear-oid nephew, Kevin Krivda, we collected some 60 spined larvae and kept them with fresh elm leaves in a large covered cardboard box in the greenhouse. This was 18 August. By 25 August most had pupated. A week later butterflies were flying all through the greenhouse. We released many by leaving the doors open but preserved a good set for future study. They were a shade on the small side either due to our drought this year, or that the Chinese elm was partly unsuitable to them as diet.

Most years large, fully grown larvae can be easily collected along the Saskatchewan River. Here they feed on Sand-bar Willow. This may be the normal food for the Mourning Cloak in these parts. Only once did I see a colony of larvae on Trembling Aspen.

There is only one other local record of Mourning Cloak larvae on Chinese Elm trees. These were about 20 feet up in the tree in August 1979. The sudden switch of an insect to a new food plant is always worth recording.

EDITOR'S NOTE: Although Mourning Cloaks prefer willows for their food-plants, they will also feed on poplars and elms, especially in urban areas where there are fewer willows. In fact in some areas they have been so involved in feeding on American Elm, (Ulmus americana)the caterpillar has been called the "Spiny Elm Caterpillar". On July 4, 1984, Bill Hausecker, of Maryfield, Saskatchewan, pointed out to me (Ronald Hooper) a colony of Mourning Cloak caterpillars in his backyard which were feeding on Siberian (Manchurian) Elm (Ulmus pumila). 